\title{
MEMBANGUN HOTSPOT MANDIRI
}

\author{
Herfia Rhomadhona $^{1)}$, Hendrik Setyo Utomo ${ }^{2)}$, Muhammad Noor ${ }^{3)}$ \\ ${ }^{1,2,3)}$ Jurusan Teknik Informatika Politeknik Negeri Tanah Laut \\ ${ }^{1)}$ herfia.rhomadhona@ politala.ac.id
}

\begin{abstract}
Abstrak: Kegiatan pengabdian masyarakat $(\mathrm{PkM})$ merupakan salah satu Tri Dharma Perguruan Tinggi, selain pendidikan, pengajaran, penelitian dan pengembangan yang wajib dilakukan oleh civitas akademik suatu perguruan tinggi. Melalui pengabdian masyarakat, jurusan teknik informatika politeknik negeri tanah laut hadir ditengah-tengah masyarakat khususnya di kabupaten tanah laut. Dengan tujuan untuk mengaplikasikan hasil pembelajaran dan penelitian di perkuliahan dan memberikan informasi kemajuan ilmu pengetahuan dan teknologi yang bermanfaat bagi masyarakat. Teknologi tepat guna yang sangat berpotensi diterapkan dalam kasus ini adalah Pelatihan membangun hotspot mandiri. Dengan adanya hotspot pada setiap usaha atau bisnis seperti rumah kos, cafe mauapun tempat nogkrong membuat masyarakat betah ditempat tersebut sembari diskusi, bertukar informasi dan mengemukakan pendapat ataupaun bersosial media. Konsumen yang sebagian besar mahasiswa lebih memilih hostpot dibandingkan membeli paket data. Selain harga lebih mudah, kek uatan signal jaringan hotspot lebih kuat dibandingkan paket data, karena tidak semua jenis paket data memiliki jangkauan luas hingga pedesaan kecuali telkomsel dengan harga yang masih terbilang mahal. Hasil dari kegiatan ini dihadiri oleh pemilik warung makan, cafe, dan warnet. Peserta antusias dalam mengikuti pelatihan hotspot, karena dapat meningkatkan keuntungan dari usaha mereka miliki.
\end{abstract}

Kata Kunci: Membangun, hotspot

\section{PENDAHULUAN}

Kegiatan pengabdian masyarakat (PkM) merupakan salah satu Tri Dharma Perguruan Tinggi, selain pendidikan, pengajaran, penelitian dan pengembangan yang wajib dilakukan oleh civitas akademik suatu perguruan tinggi. Melalui pengabdian masyarakat, jurusan teknik informatika politeknik negeri tanah laut hadir ditengah-tengah masyarakat khususnya di kabupaten tanah laut. Dengan tujuan untuk mengaplikasikan hasil pembelajaran dan penelitian di perkuliahan dan memberikan informasi kemajuan ilmu pengetahuan dan teknologi yang bermanfaat bagi masyarakat.

Pesatnya perkembangan teknologi informasi yang tidak dapat dihindari dan seakan mendesak masyarakat untuk mengikuti perkembangan ilmu pengetahuan dan teknologi. Layaknya komputer dan internet yang semula merupakan kebutuhan sekunder sekarang berubah menjadi kebutuhan primer masyarakat. Karena setiap inovasi diciptakan untuk memberikan manfaat positif bagi kehidupan masyarakat. Memberikan banyak kemudahan, serta sebagai cara baru dalam melakukan aktifitas sehari-hari di masyarakat kota maupun pedesaan.

Potensi perkembangan komputer yang juga sudah merambah ke berbagai desa di kabupaten tanah laut, terutama di desa panggung sekitar kampus politeknik negeri tanah. Internet atau hotspot pada umumnya sering kita temui di sekitar lingkungan kampus, hotel, cafe dan di tempat nongkrong (alun-alun) yang ada di kota 
kabupaten yang menyediakan layanan internet tanpa kabel tersebut. Hal ini disebabkan banyaknya perangkat yang telah dilengkapi dengan teknologi wireless, sehingga tren penggunaannya pun semakin tinggi. Namun, tidak semua orang mengerti bagaimana cara membangun hotspot tersebut. Kurangnya informasi dan biaya pembangunan infrastruktur Wifi yang agak mahal membuat para pemilik usaha enggan untuk membangun hotspot. Padahal adanya hotspot ini sangat berpotensi untuk menambah daya tarik konsumen dan bisa menambah penghasilan dari tempat usaha yang dimiliki.

Oleh karena itu, teknologi tepat guna yang sangat berpotensi diterapkan dalam kasus ini adalah Pelatihan membangun hotspot mandiri. Dengan adanya hotspot pada setiap usaha atau bisnis seperti rumah kos, cafe mauapun tempat nogkrong membuat masyarakat betah ditempat tersebut sembari diskusi, bertukar informasi dan mengemukakan pendapat ataupaun bersosial media. Konsumen yang sebagian besar mahasiswa lebih memilih hostpot dibandingkan membeli paket data. Selain harga lebih mudah, kekuatan signal jaringan hotspot lebih kuat dibandingkan paket data, karena tidak semua jenis paket data memiliki jangkauan luas hingga pedesaan kecuali telkomsel dengan harga yang masih terbilang mahal.
Berdasarkan latar belakang tersebut, maka perlu dilakukan adanya pelatihan membangun hotspot mandiri di desa Pangungu Kecamatan Pelaihari Kabupaten Tanah Laut. Adapun tujuan dari kegiatan pelatihan ini adalah: (1) Turut serta dalam pengembangan internet murah di masyarakat. (2) Membangun komunitas yang sadar akan kehadiran manfaat teknologi informasi dan internet. (3) meningkatkan nilai tambah pendapatan masyarakat yang memiliki usaha. (4) penerapan ilmu pengetahuan dan teknologi di masyarakat melalui kegiatan pengabdian kepada masyarakat.

\section{METODE PEMBUATAN HOTSPOT}

Kegiatan pengabdian kepada masyarakat berupa pelatihan Membangun Hotspot Mandiri, dilaksanakan di Desa Panggung Kecamatan Pelaihari Kabupaten Tanah Laut. Kegiatan ini dilaksanakan pada tanggal 21 Juli 2017 bertempat di Laboratorium Komputer Jurusan Teknik Informatika di Politeknik Negeri Tanah Laut.

Kegiatan Pelatihan Membangun Hotspot Mandiri dengan peserta berjumlah 25 orang dibagi menjadi tiga tahap yakni penjelasan tentang internet secara umum, pelatihan (praktek) dan tanya jawab peserta.

Pada tahap penjelasan, peserta diberi wawasan mengenai betapa pentingnya 
internet dalam penyebaran informasi dan wawasan tentang prospek usaha yang melibatkan teknologi informasi disetiap usaha kita. Di kabupaten Tanah Laut, Desa Panggung khususnya belum ada tempat usaha (cafe, restoran, kos-kosan) yang menggunakan hotspot. Sementara itu, konsumen tempat usaha sebagaian besar adalah mahasiswa. Kebanyakan diantara mereka lebih memilih hotspot dibandingkan kuota paket data yang masih terbilang mahal.

Beberapa hal penting yang perlu dipersiapkan untuk membangun hotspot yaitu:

\section{Menentukan konsep hotspot}

Konsep hotspot merupakan awal yang harus ditentukan, karena menyangkut perencanaan infrastruktur hotspot. Ada 2 (dua) teknik pemasangan hotspot yang biasa digunakan di cafe-cafe atau tempat belanja atau hotel yaitu hotspot dapat digunakan secara gratis dengan sistem login atau dengan voucher menggunakan sistem pembayaran per 2 jam, per 6 jam, atau per 8 jam.

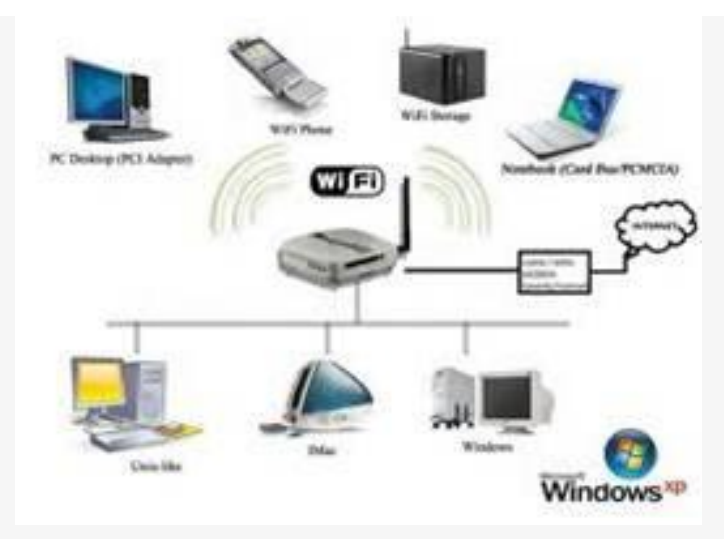

Gambar 1. Infrastruktur hotspot

2. Akses internet yang cukup

Hal pertama yang harus dimiliki adalah akses internet. Pada pelatihan ini menggunakan layanan indihome kecepatan paling rendah yaitu paket unlimited 1 Mbps dengan biaya langganan bulanan $\mathrm{R}$. 375.000/bulan

Selain itu, antara lain :

1. Router

2. Hub/S witch

3. Access Point

4. Modem

5. Kabel UTP dan konektor RJ45

\section{HASIL}

Berikut topologi jaringan untuk membuat Konfigurasi Jaringan Hotspot di Mikrotik dengan Winbox. Winbox adalah sebuah software yang digunakan untuk meremote sebuah server mikrotik kedalam mode GUI (Graphical User Interface) melalui operating system windows. 
Adapun tahapan untuk membangun hotspot yakni:

1. Pastikan memiliki koneksi internet

2. Pasangkan koneksi internet ke port 1 pada routerboard

3. Pasangkan koneksi dari routerboard ke komputer yang digunakan untuk setting mikrotik

4. Kemudian jalankan winbox untuk

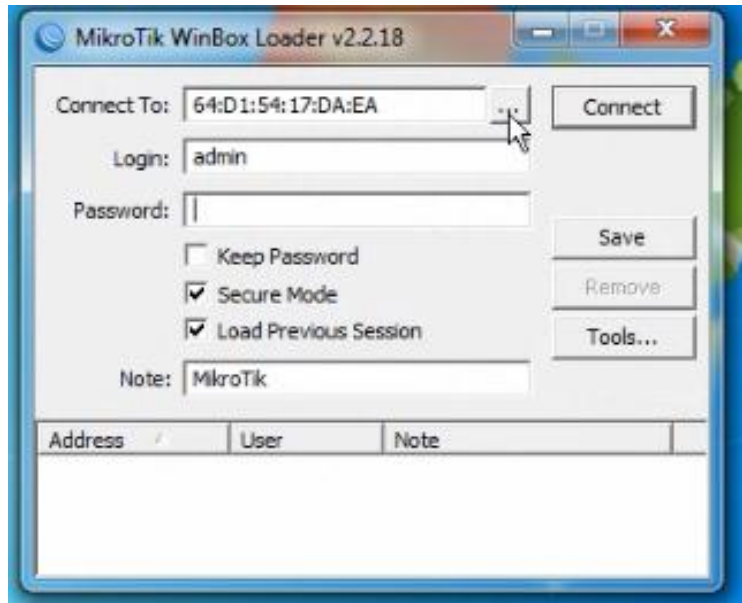

Gambar 4. Login winbox konfigurasi jaringan hotspot

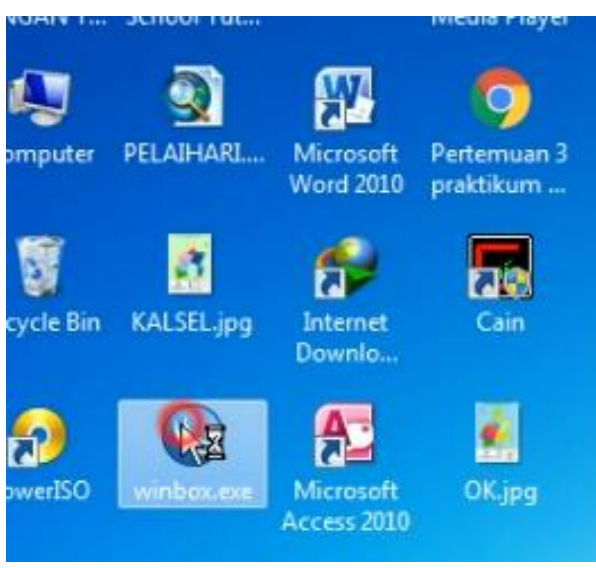

Gambar 2. Icon winbox

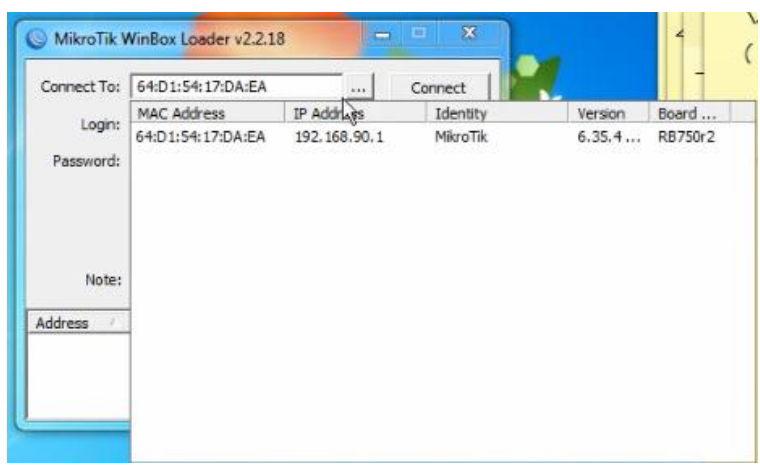

Gambar 3. Koneksi winbox

5. Setelah memilih Mac Address, login menggunakan default yaitu : Login: Admin dan Password dikosongin saja.
6. Setelah berhasil login, maka akan muncul layar winbox seperti berikut

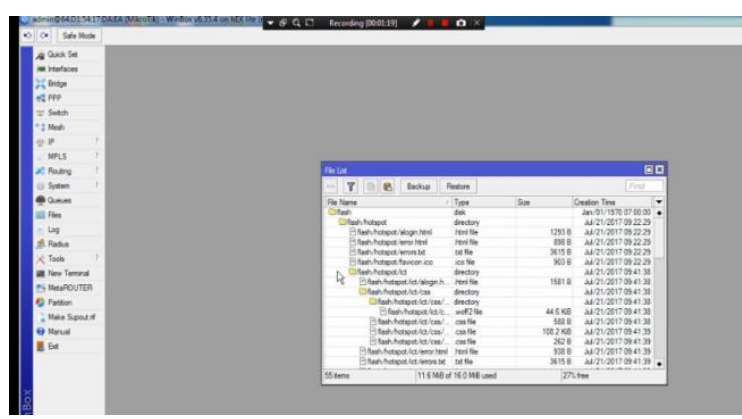

Gambar 5. Layar winbox

7. Kemudian pilih new terminal untuk reset mikrotik dengan cara : /system reset-configuration no $=$ defaults $=$ yes Reset mikrotik ini bertujuan mengembalikan pengaturan dasar pabrikan awal. 


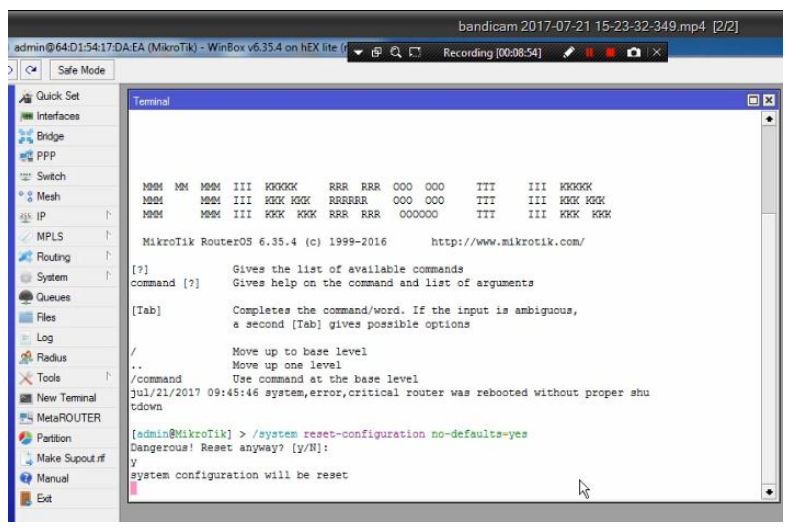

gambar 6. Perintah reset mikrotik

8. Selanjutnya kita masuk ke menu interfaces. Ubahlah nama interfaces agar mudah melakukan konfigurasi. Contoh ether1(internet) dan ether2(client).
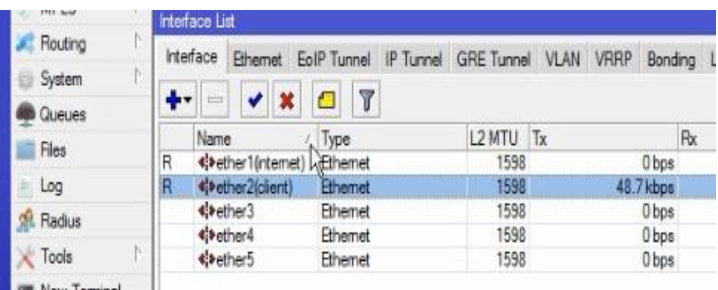

Gambar 7. Konfigurasi LAN Card

9. Untuk menambahkan IP pada ether1(internet) dan ether2(client), dengan menggunakan menu IP kemudian pilih Address kemudian pilih (klik) tanda tambah (+) dipojok kiri atas, isikan address, network dan interface seperti pada gambar kemudian tekan apply atau ok.

Dalam percobaan kali ini IP address 172.86.0.50/16 untuk ether1(internet) dan IP address 192.168.1.90/24 untuk ether2(client)

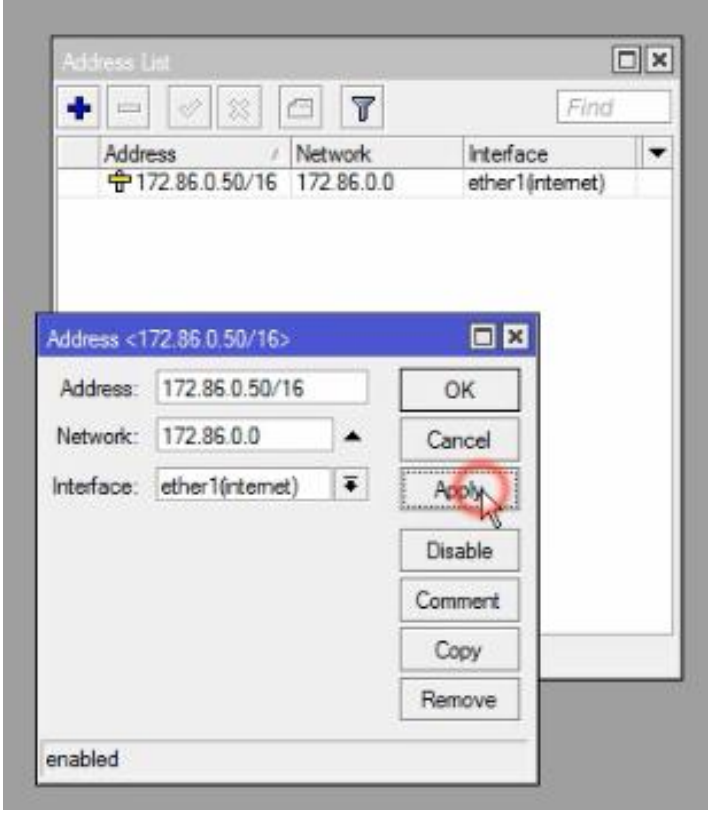

Gambar 8. Konfigurasi IP address

10. Mengatur IP DNS pada menu address $\rightarrow$ DNS. Isikan IP ether1(internet) sebagai server, seperti gambar berikut.

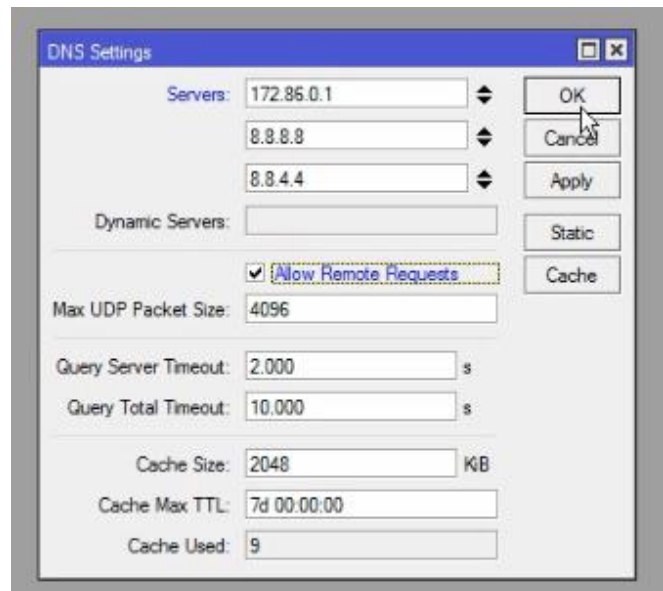

Gambar 9. Konfigurasi DNS 
11. RouteList

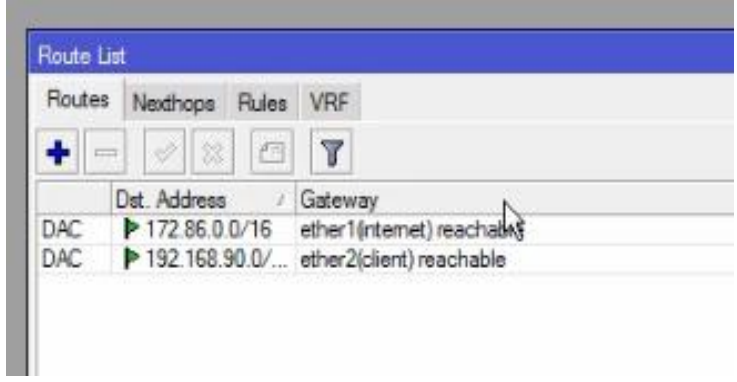

Gambar 10. Hasil konfigurasi routing

12. Firewal; kemudian atur pada menu NAT dan Action (masquerade)

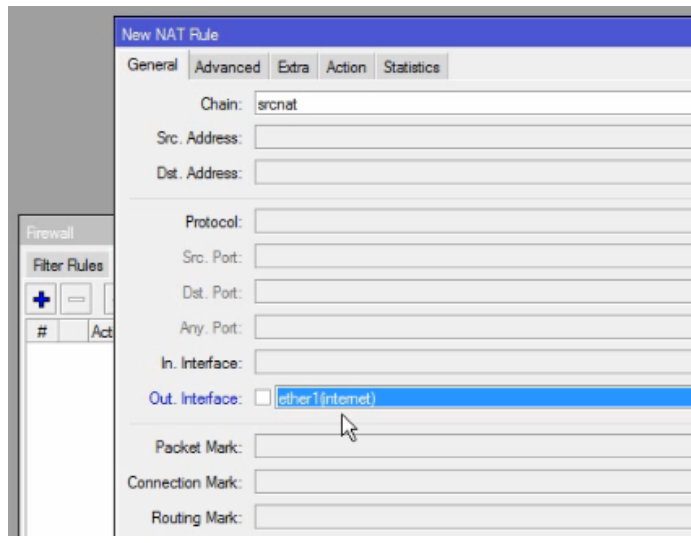

Gambar 11. Konfigurasi firewall

13. Selanjutnya samakan alamat ip address client (komputer kita) dengan ip yang telah disetting pada winbox

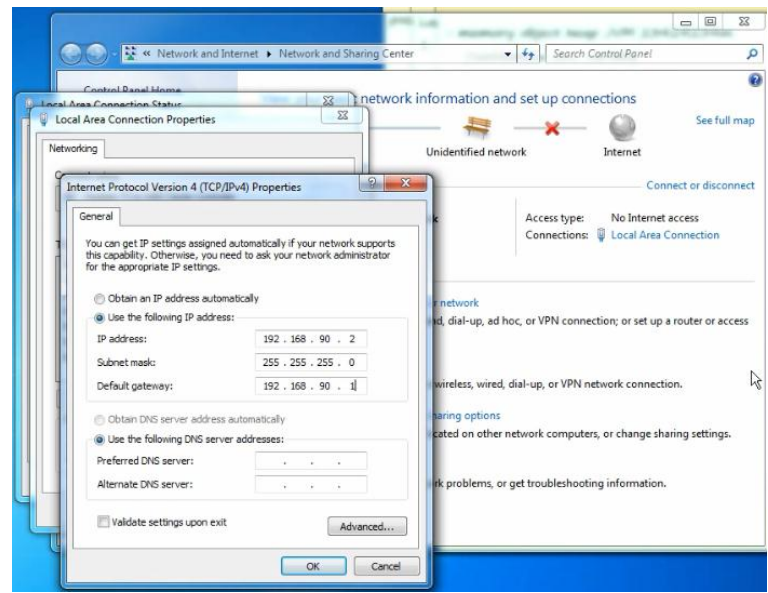

Gambar 12. Uji coba client
14. Setelah selesi mengkonfigurasi IP client, selanjutnya penulis akan membuat hotspot melalui menu IP $\rightarrow$ Hotspot $\rightarrow$ Hotspot Setup pada aplika si winbox.

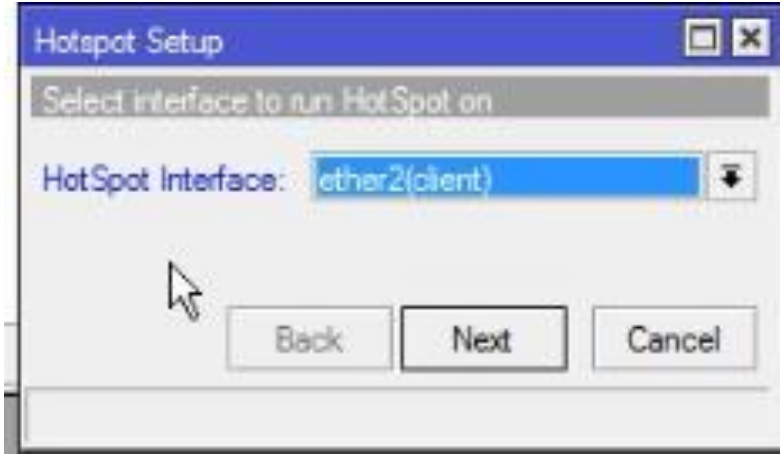

Gambar 13. Setup hotspot

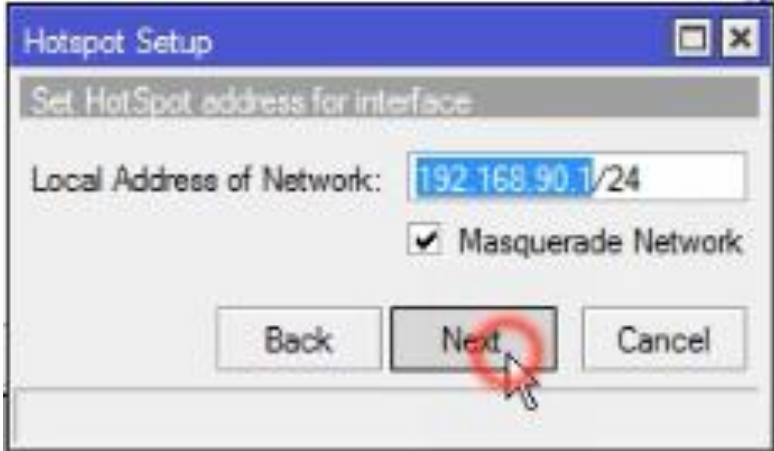

Gambar 14. Set hotspot address untuk interface

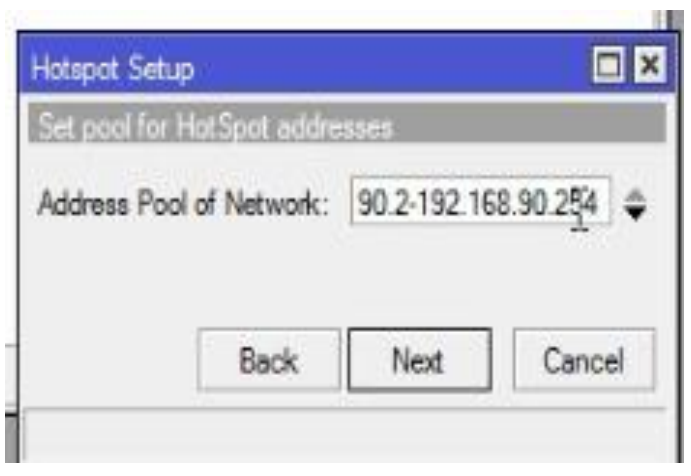

Gambar 15 Setup address pool 


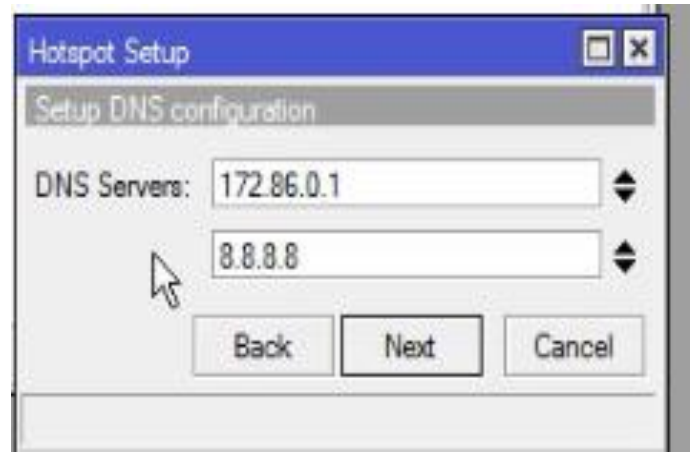

Gambar 16 Setup konfigurasi DNS

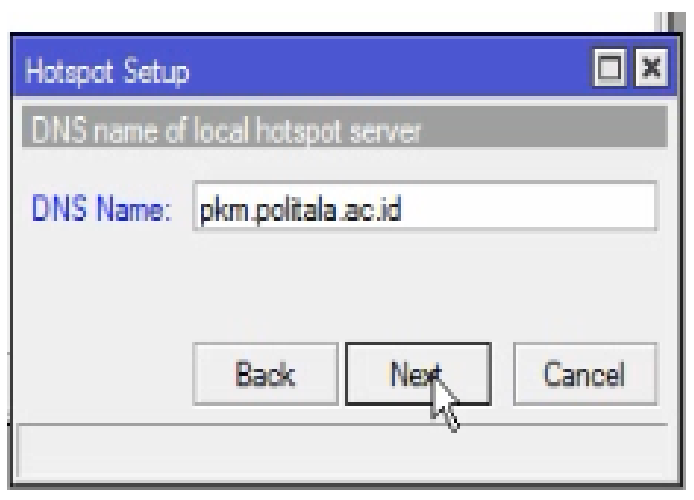

Gambar 17 konfigurasi DNS name

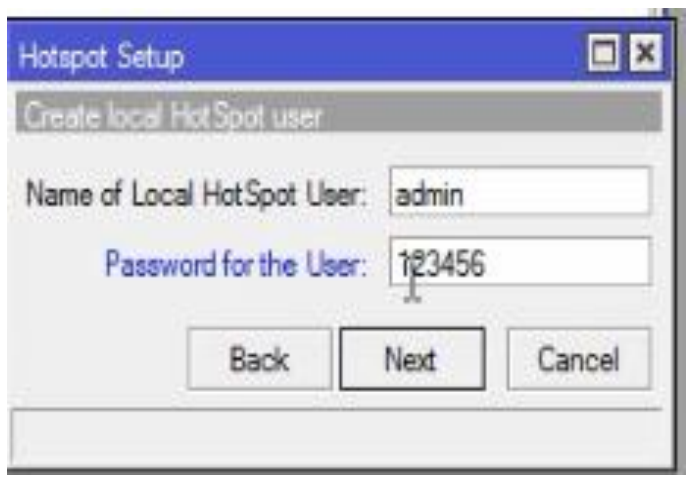

Gambar 18 konfigurasi create local hotspot

user

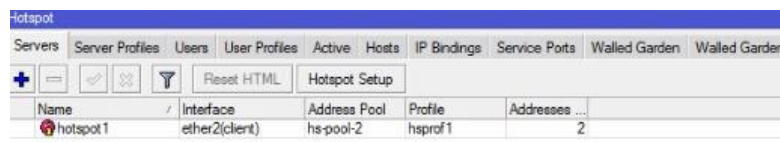

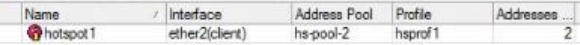

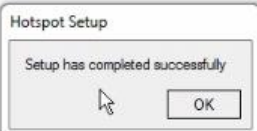

Gambar 19 hasil konfigurasi hotspot

15. Sekarang konfigurasi pada server profile, untuk menghilangkan cookie seperti yang ditunjukkan pada gambar berikut.

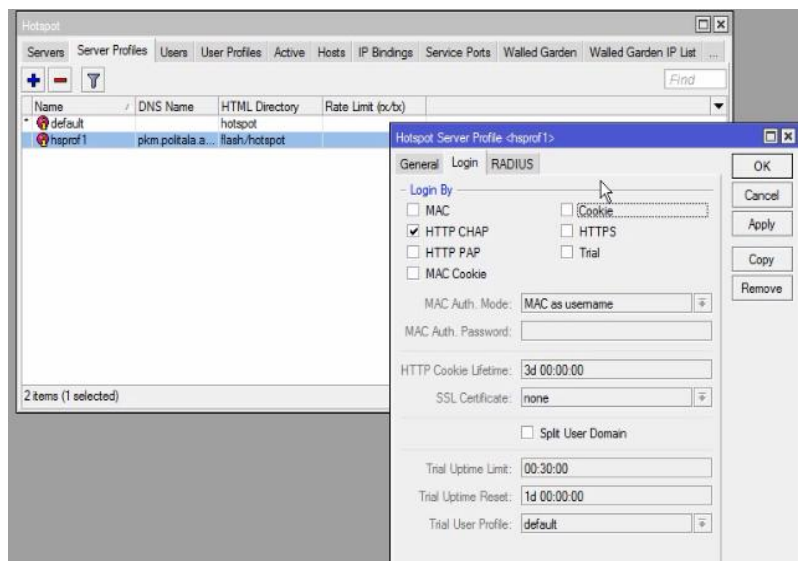

Gambar 20 menonaktifkan cookie

16. Tampilan uji coba hotspot pada komputer user

pkm.politala.acid/login?dst=http\%3A\%2F\%2Fwww.detik.com\%2F

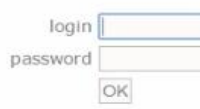

HOTSPOT GATEWAY omentow Mikromik

Gambar 21 uji coba hotspot pada client

17. User profile, pada percobaan kali ini sebagai contoh name diisi siswa dengan memberikan rate limit sebesar $1 \mathrm{M} / 512 \mathrm{k}$ 


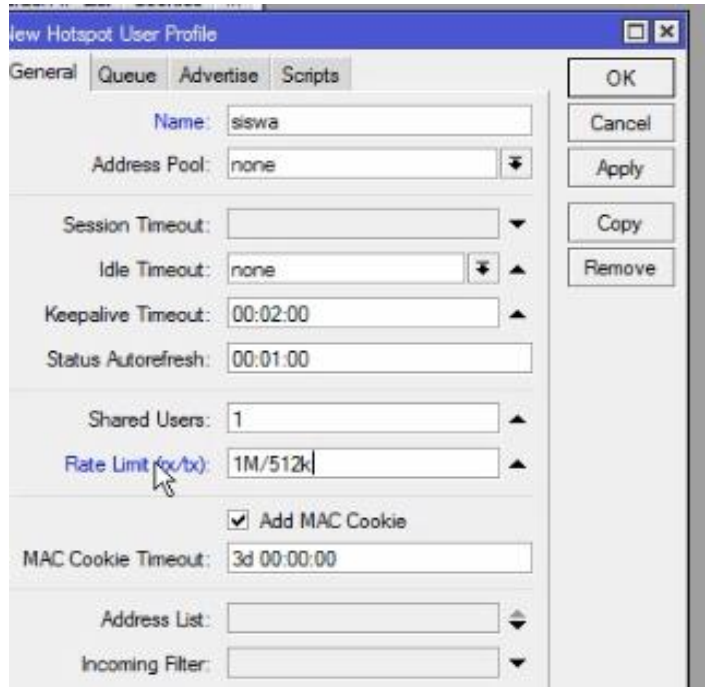

Gambar 22. Konfigurasi bandwidth

18. Selanjutnya penulis akan membuat user lebih banyak lagi melalui menu User pada jendela Hotspot setup. Isikan Name sebagai user dan passw ord untuk kode pengamnan.

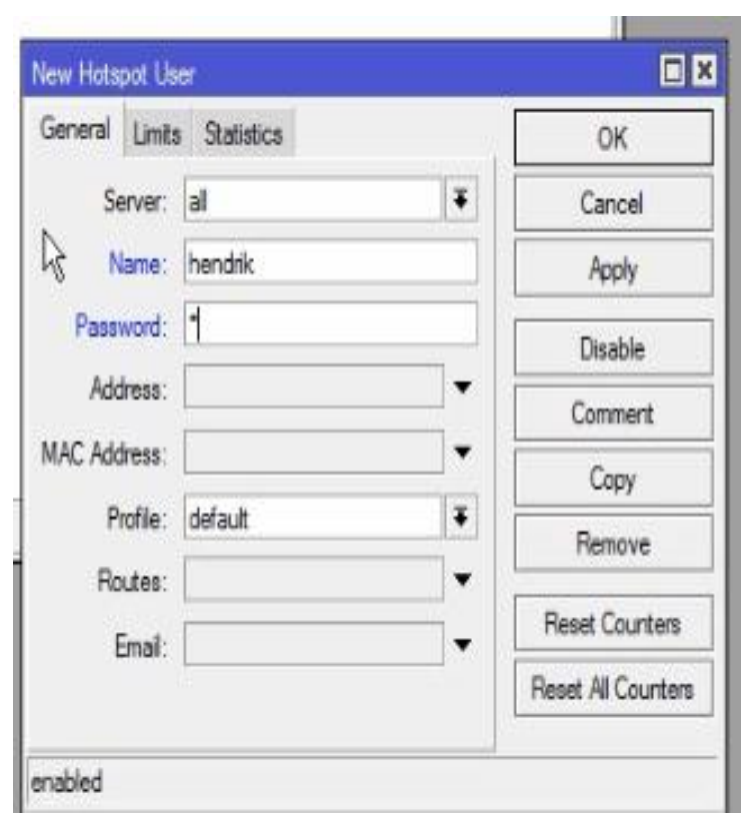

Gambar 23. Konfigurasi user baru

19. Penulis membuat user hotspot sebanyak 2 user, seperti dibawah ini.

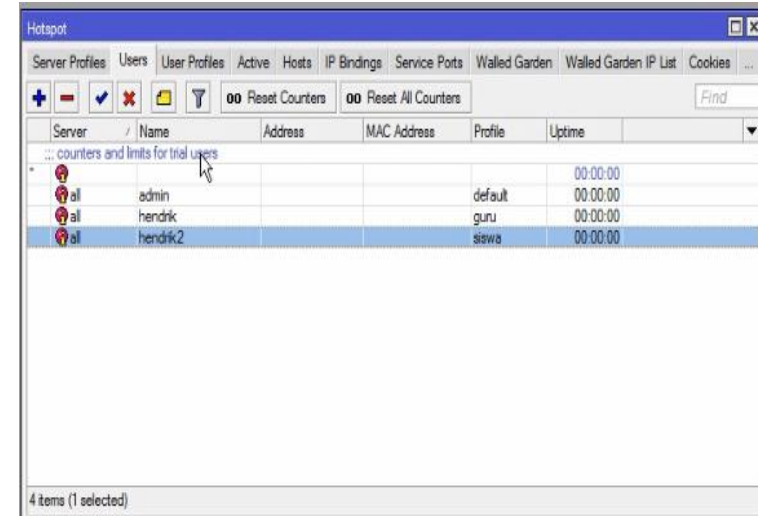

Gambar 24 aktivitas user yang login

20. Setelah itu lakukan percobaan pada client yang sudah terkoneksi dengan access point. Dengan membuka browser ketidk www.detik.com, maka secara otomatis akan direct ke pkm.politala.ac.id karena itu DNS Name yang telah dikonfigurasi.

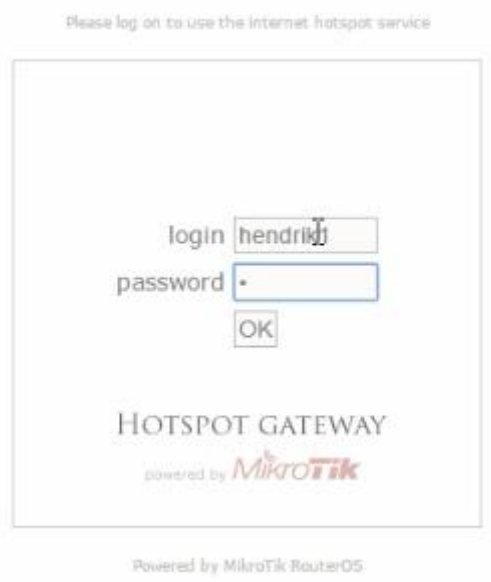

Gambar 25 tampilan awal login pada komputer user

21. Sekarang internet sudah bisa dijalankan, saat user mengisi login dan password maka tampilan website detik.com muncul. 


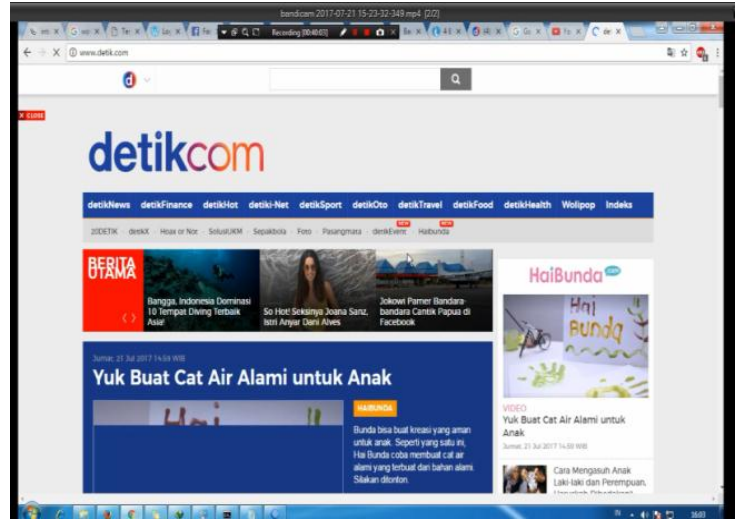

Gambar 26. Hasil uji coba browsing

\section{KESIMPULAN}

Hasil dari kegiatan ini dihadiri oleh pemilik warung makan, cafe, dan warnet. Peserta yang mengikuti pelatihan sebanyak 25 peserta. Peserta antusias dalam mengikuti pelatihan hotspot, karena dapat meningkatkan keuntungan dari usaha mereka miliki. Selama pelatihan peserta mengikuti dengan baik dan melakukan komunikasi dua arah antara intrukstur ke peserta pelatihan.

\section{DAFTAR PUSTAKA}

Andi, MADCOMS. (2009) Panduan Lengkap Membangun Sistem Jaringan Komputer, Yogyakarta: Andi, Madiun:

\section{MADCOMS}

Prasandika, A. (2014). Perancangan Hotspot Area Berbasis Mikrotik dan Radius (Studi Kasus : Warnet Kadipiro). Yogyakarta: STMIK Amikom Yogyakarta.
Purbo, O. W. (2006). Buku Pegangan Internet Wireless dan Hotspot. Jakarta: CHIP

http://ww w.kotainternet.com/peluang-

bisnis-hotspot.htm 